\section{Fatal Yellow Fever in a Traveler Returning From Peru - New York, 2016}

Alexandra P. Newman, DVM ${ }^{1}$; Rebecca Becraft ${ }^{2}$; Amy B. Dean PhD 3 ; Rene Hull ${ }^{3}$; Bryon Backenson, MS ${ }^{1}$; Gillian Hale, MD ${ }^{4}$; Janeen Laven ${ }^{5}$; Julu Bhatnagar, $\mathrm{PhD}^{4}$; J. Erin Staples, $\mathrm{MD}, \mathrm{PhD}^{5}$

In October 2016, a male New York resident aged 74 years developed fever, myalgia, nausea, and vomiting while traveling in Peru, 3 days after visiting the northern Amazon area. During the next 2 days, he experienced fever, abdominal pain, and watery diarrhea and was admitted to a hospital in Peru, where Entamoeba histolytica was detected in his stool. He was treated with intravenous fluids and antibiotics and released 1 day after admission. His condition worsened, however, and he returned to New York and immediately sought care at a hospital emergency department, where he was found to be afebrile, slightly confused, and jaundiced. Laboratory tests revealed leukopenia, thrombocytopenia, acute renal failure, liver dysfunction, and a metabolic acidosis (Table). He was transferred from the emergency department to a tertiary care center, where he was admitted and received intravenous fluids, antibiotics, and hemodialysis. During the next 2 days, he developed melena and disseminated intravascular coagulation. He experienced multiple episodes of ventricular fibrillation and died 3 days after admission. Autopsy revealed gastrointestinal hemorrhage and subtotal hepatocellular necrosis. Testing for selected viral, bacterial, and parasitic agents was negative, except for antibody to Salmonella H type A/B (Table). He had not received yellow fever vaccine before traveling. Serum specimens and tissues were sent to Wadsworth Center, the New York State Public Health Laboratory, and CDC to test for yellow fever virus and other pathogens.

A serum specimen collected 7 days after illness onset tested positive for flaviviral RNA by reverse transcription-polymerase chain reaction (RT-PCR), and the amplicon sequencing was consistent with yellow fever virus. A serum specimen obtained at autopsy was positive for yellow fever immunoglobulin M antibodies. Yellow fever RT-PCR assays performed on RNA extracted from formalin-fixed, paraffin-embedded liver tissue were positive; amplicon sequence analysis revealed highest identity with wild-type yellow fever virus strains. An immunohistochemical assay for yellow fever virus performed on the liver tissue demonstrated staining of necrotic hepatocytes throughout the lobules, without mesenchymal staining. The morphologic features of fulminant active hepatitis and the immunohistochemical staining pattern and sequencing results, in combination with the patient's travel history to a region
TABLE. Clinical laboratory results* and infectious disease test results for patient with a fatal case of yellow fever — New York, 2016

\begin{tabular}{lcc}
\hline Laboratory test & Result & Reference range \\
\hline White blood cell count & $3,600^{\dagger}$ & $3,800-10,600 / \mu \mathrm{l}$ \\
Platelet count & $5,300^{\dagger}$ & $150,000-400,000 / \mu \mathrm{l}$ \\
Bicarbonate & $10^{\dagger}$ & $22-303 \mathrm{mmol} / \mathrm{L}$ \\
Sodium & 135 & $134-145 \mathrm{mmol} / \mathrm{L}$ \\
Potassium & $5.7^{\dagger}$ & $3.5-5.1 \mathrm{mmol} / \mathrm{L}$ \\
Blood urea nitrogen & $151^{\dagger}$ & $9-20 \mathrm{mg} / \mathrm{dL}$ \\
Creatinine & $13.7^{\dagger}$ & $0.8-1.5 \mathrm{mg} / \mathrm{dL}$ \\
Alanine amino transferase & $3,584^{\dagger}$ & $21-72 \mathrm{U} / \mathrm{L}$ \\
Aspartate amino transferase & $3,596^{\dagger}$ & $17-59 \mathrm{U} / \mathrm{L}$ \\
Total bilirubin & $11.8^{\dagger}$ & $0.0-1.0 \mathrm{mg} / \mathrm{dL}$ \\
Alkaline phosphatase & $349^{\dagger}$ & $38-126 \mathrm{U} / \mathrm{L}$ \\
Albumin & 3.4 & $3.5-5.0 \mathrm{~g} / \mathrm{dL}$ \\
Lactic acid & $3.6^{\dagger}$ & $0.7-2.1 \mathrm{mmol} / \mathrm{L}$ \\
Bacterial cultures (blood) & No growth & No growth \\
Leptospiral DNA (urine) & Not detected & Not detected \\
Dengue viral RNA (serum) & Not detected & Not detected \\
Salmonella H type A/B antibodies & Positive ${ }^{\dagger}$ & Negative \\
(serum) & & \\
Q fever antibodies (serum) & Negative & Negative \\
Hepatitis A virus antibodies (serum) & Nonreactive & Nonreactive \\
Hepatitis B virus antibodies (serum) & Nonreactive & Nonreactive \\
Hepatitis C virus antibodies (serum) & Nonreactive & Nonreactive \\
Yellow fever virus & Positive ${ }^{\dagger}$ & Negative \\
immunoglobulin M antibodies & & \\
Yellow fever virus neutralizing & $640^{\dagger}$ & $<10$ \\
antibodies & & \\
\hline
\end{tabular}

* Upon hospital admission.

† Outside the reference range.

of Peru where yellow fever is endemic, lack of yellow fever vaccination, and clinical history supported the diagnosis of infection with wild-type yellow fever virus (1).

Yellow fever is a mosquitoborne viral disease endemic to sub-Saharan Africa and tropical areas of South America. Most infections are asymptomatic or result in a nonspecific febrile illness. The severe form of yellow fever results in jaundice and hemorrhage; approximately $50 \%$ of severe cases are fatal (2).

During 1970-2015, 11 yellow fever cases were reported among U.S. and European travelers (3). Before the current case, the last yellow fever case diagnosed in a U.S. resident was in 2002 (4). However, after large outbreaks in Africa and South America during 2016-2017, the number of cases confirmed in travelers from countries without endemic yellow fever transmission increased substantially, including at least 11 workers infected in Angola; two travelers in Peru; one each in Suriname and Bolivia; and this case $(5,6)$.

No specific treatment for yellow fever exists; care is based on symptoms. Prevention of infection is through vaccination and avoidance of mosquito bites. Yellow fever vaccine is recommended for persons aged $\geq 9$ months who are traveling 
to or living in areas at risk for yellow fever virus transmission (3). However, because serious adverse events can occur after yellow fever vaccination, contraindications and precautions to vaccination, such as patient age, should be considered before administering the vaccine. Health care providers should consider and test for yellow fever in unvaccinated persons with fever and jaundice or hemorrhage who live in or have traveled to an area with yellow fever virus transmission. Information on current yellow fever outbreaks and vaccination requirements and recommendations for specific countries are available on CDC Travelers' Health website (https://www.cdc.gov/travel/).

\section{Conflict of Interest}

No conflicts of interest were reported.

\footnotetext{
${ }^{1}$ New York State Department of Health; ${ }^{2}$ Chemung County Health Department, Elmira, New York; ${ }^{3}$ Wadsworth Center, New York State Department of Health; ${ }^{4}$ Division of High-Consequence Pathogens and Pathology, National Center for Emerging and Zoonotic Infectious Diseases, CDC; ${ }^{5}$ Division of Vector-borne Diseases, National Center for Emerging and Zoonotic Infectious Diseases, CDC, Ft. Collins, Colorado.
}

Corresponding author: Alexandra Newman, alexandra.newman@health.ny.gov.

\section{References}

1. Martines RB, Bhatnagar J, Kanamura CT, et al. Difference in viral antigens distribution between wild type and vaccine-associated viscerotropic yellow fever fatal cases. International Conference on Emerging Infectious Diseases; August 24-26, 2015; Atlanta, GA.

2. Johansson MA, Vasconcelos PF, Staples JE. The whole iceberg: estimating the incidence of yellow fever virus infection from the number of severe cases. Trans R Soc Trop Med Hyg 2014;108:482-7. https://doi. org/10.1093/trstmh/tru092

3. Gershman MD, Staples JE. Yellow fever. In: Brunette GW, ed. CDC health information for international travel 2016. New York, New York: Oxford University Press; 2016.

4. CDC. Fatal yellow fever in a traveler returning from Amazonas, Brazil, 2002. MMWR Morb Mortal Wkly Rep 2002;51:324-5.

5. European Centre for Disease Prevention and Control. Yellow fever among travellers returning from South America-14 March 2017. Stockholm, Sweden: European Centre for Disease Prevention and Control; 2017. https:// ecdc.europa.eu/en/publications/Publications/14-03-2017-RRA-Yellow\%20 fever,\%20Flaviviridae-Suriname,\%20Southern\%20America.pdf

6. Wang L, Zhou P, Fu X, et al. Yellow fever virus: increasing imported cases in China. J Infect 2016;73:377-80. https://doi.org/10.1016/j. jinf.2016.07.003 